\title{
One-time injection of calcitonin induces glucose intolerance in children with the 1-st degree obesity
}

\author{
S. S. Moisa ${ }^{1}$, A. D. Nozdrachev ${ }^{2}$ \\ ${ }^{1}$ Federal State-Financed Establishment of Science State Scientific Center of Russian Federation Institute of Biomedical Problems of \\ the Russian Academy of Sciences, Moscow, Russia; butalana07@list.ru \\ ${ }^{2}$ Institute of Physiology Named by I.P.Pavlov of the Russian Academy of Sciences, Sanct-Petersburg, Russia
}

Received 14 November 2012; revised 4 April 2013; accepted 5 May 2013

Copyright (C) 2013 S. S. Moisa, A. D. Nozdrachev. This is an open access article distributed under the Creative Commons Attribution License, which permits unrestricted use, distribution, and reproduction in any medium, provided the original work is properly cited.

\begin{abstract}
The effect of calcitonin on the blood glucose level in glucose-tolerance test of children with the 1-st degree obesity was studied. Initial blood glucose level was normal and glucose-tolerance test per os didn't expose glucose tolerance impairment in children under control. Calcitonin didn't change initial glucose concentration but evoked impairment of glucose tolerance. The girls with the 1-st degree obesity were more sensitive to hyperglycemic effect of calcitonin than the boys. Sex specificities must be taken into consideration in calcitonin treatment. Besides one ought mean that the increasing secretion of calcitonin occurs in stress-reactions. In these conditions endogenous calcitonin can make the same effect on the regulation of carbohydrate metabolism as exogenous injections of hormone.
\end{abstract}

Keywords: Calcitonin; Obesity; Carbohydrate Metabolism; Hyperglycemia; Glucose-Intolerance

\section{INTRODUCTION}

It is known that human health is formed in early childhood, when the cause for future diseases can be established, including the metabolic syndrome and diabetes, the main factor in the development of which is the child's excess weight, moreover, obesity is strongly associated with postnatal growth. The body weight of the child is very dependent on the particular stage of growth. It is important to take into account the age at which the fat is reduced. Thus, a decrease in fat at an early age (1 6 years) causes obesity in adult life [1]. An increased body mass index at 10 years and obesity in childhood are risk factors for the subsequent development of mellitus type I diabetes [2], and a moderate decrease in body weight significantly reduces the incidence of the metabolic syndrome [3]. Several studies have shown that the most important factor leading to a reduction of a receptor's own sensitivity to insulin is obesity [4-7]. Lofgren R. [8] believes that the insulin-resistance of adipocytes is a consequence of obesity. The correlation between the amount of abdominal fat and insulin-resistance is established [9]. Childhood obesity in 30\% of the cases determines obesity in adulthood, which has a more complicated form than in the development of obesity in adult life [10]. In children and adolescents with obesity, a variety of endocrine and metabolic disorders are identified, although, until recently, many believed that similar violations are observed only in adult obesity [11]. In children with obesity, metabolic disorders were identified, such as insulin-resistance and dyslipidemia of an atherogenic nature, which increase with obesity [12]; they have a violated metabolism of glucose, lipids, uric acid [13], elevated levels of insulin, $C$-peptide [14], and free fatty acids in the blood plasma [15].

Abdominal type of obesity is often combined with insulin-resistance [16] and the development of the progressive metabolic syndrome [17]. Abdominal obesity in prepubertal children, mostly, is subcutaneous, while the level of visceral fat increases with age and puberty [18, 19]. By the time of puberty, the content of insulae tissue in the pancreas is reduced to $1 \%-2 \%$ and remains stable for a long time.

Overweight and obesity both in adults, children, and adolescents is a risk factor for mellitus diabetes, arterial hypertension, early atherosclerosis, and reproductive disorders [20-22]. In addition, obesity in childhood leads to the development of associated diseases such as mellitus type II diabetes, hypertension, dyslipidemia, sleep apnea, and fatty liver disease [23-27]. It is believed that children and adolescents with obesity may develop the metabolic syndrome $[28,29]$; in turn, the pathological basis of the 
metabolic syndrome is a decreased sensitivity to insulin that occurs in obesity [30]. At the same time, insulinresistance in obese children is an important marker for the risk of mellitus type II diabetes and its complications [31]. The development of mellitus diabetes in children is associated with viral infections, stressful events, puberty, and an increase of the incidence of mellitus diabetes occurs between the age of 10 - 14 years [20,32].

Previously [33] a calcitonin diabetogenic effect and its role as a "risk factor" in the development of metabolic syndrome and diabetic mellitus are discussed. However, clinical observations for the patients with Paget's disease and a long-time calcitonin treatment are not identical [34-36]. Some authors [34] describe the hyperglycemic effect of synthetic salmon calcitonin and the existence of a strong reverse correlation between plasma calcium level and glucose level, and others [35,36] didn't reveal the symptoms of diabetes mellitus in patients with Paget's disease even after 8 years of calcitonin treatment. These data allow suppose that diabetic effect of calcitonin reveals not always, but, apparently, under the changing of the initial state of pancreas $\beta$-cells, especially under their intensive activity. With the number of factors predisposed to diabetes mellitus belongs, as it is known, obesity. This metabolism disturbance accompanies by the increasing of organism need in insulin and intensified functioning of islet's apparatus leading to the following exhaustion. Proceeding from these conceptions it is admitted suppose that under obesity calcitonin excess can do a diabetogenic effect sooner than under normal metabolism state. In this connection the aim of our investigation was to study the effect of one-time injection of calcitonin on glucose tolerance in children with the 1st degree obesity.

\section{METHOD OF INVESTIGATION}

20 children (10 boys and 10 girls) with the 1-st degree obesity and negative calcium balance in age of 10 - 14 years, which were prescript preparation "Calcitrin” for the normalization of bone metabolism, were inspected. The calculation of body mass index (BMI) for the height and weight is the most standardized method of the definition of degree obesity. The diagnosis of child obesity were defined under BMI $>30 \mathrm{~kg} / \mathrm{m}^{2}[16,17]$. In inspected children BMI calculated with the formula: BMI $=$ body mass $(\mathrm{kg}) /$ height $^{2}(\mathrm{~m})$. If body mass increased 91-st percentile for this age and sex for $10 \%-29 \%$ it is established the 1-st degree obesity. Body mass of examined children was increased the necessity one for $15 \%$ $25 \%$ that corresponds the 1-st degree obesity. It is used indirect (endogenous) method of estimation of biological insulin effect, vectored to the assessment of endogenous insulin effect glucose tolerance test per os admitting to reveal the earlier disturbances of carbohydrate metabo- lism-the sensitivity of the peripheral tissues to insulin. In each child under test twice defined the tolerance to glucose: in control research (glucose load) and against the background of preliminary (for 30 - 35 min before glucose load) intramuscular injection 15 units of calcitrin. Glucose load per os calculated for the nomogram of computation of body surface on height and weight (by Graford, Terry and Rurk) and contained from 60 to $100 \mathrm{~g}$ glucose. Blood glucose determined with titrometric method of Hagedorn and Iensen before load and also every 30 min during 3 hours after it. For the estimation of glycaemic curves it was calculated hyperglycaemic (ratio of maximal blood glucose level by initial level) and hypoglycaemic (ratio of minimal blood glucose level by initial level) coefficients. The results of fulfilling inspections are represented in Figures 1 and 2.

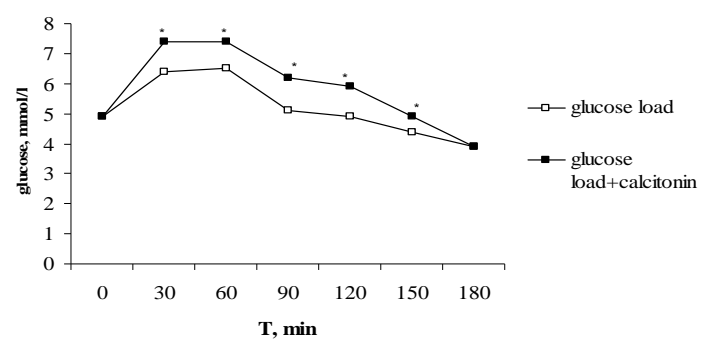

Figure 1. Effect of one-time calcitonin injection on the type of alimentary hyperglycaemia in children with the 1-st degree obesity. ${ }^{*}$ The reliability of results difference under control and against the background of calcitonin.

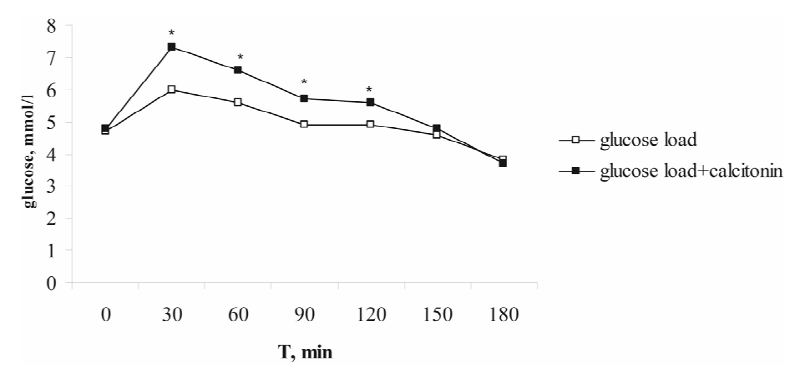

(a)

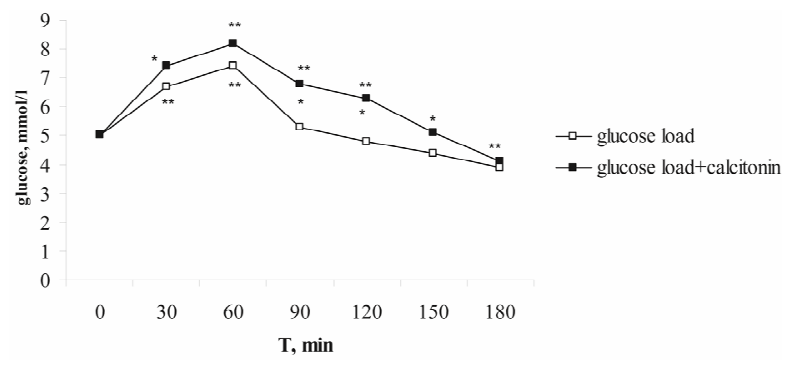

(b)

Figure 2. Sex differences of alimentary hyperglycaemia in children with the 1-st degree obesity under control and against the background of calcitonin. (a) Boys; (b) Girls. *The reliability of results differences under control and against the background of calcitonin; ${ }^{* *}$ the reliability of sex differences under control and against the background of calcitonin. 


\section{RESULTS AND DISCUSSION}

Initial level of blood glucose in control was normal (Figure 1). Maximal content of blood glucose (6.5 \pm 0.5 $\mathrm{mmol} / \mathrm{l}$ ) achieved in $60 \mathrm{~min}$ after glucose load, then it decreased by initial value to $120 \mathrm{~min}$ and by hypoglycaemic level (3.9 $\pm 01 \mathrm{mmol} / \mathrm{l})$ to $180 \mathrm{~min}$ after load.

In the investigation with calcitonin injection the initial blood glucose concentration didn't change. But already in $30 \mathrm{~min}$ after load it increased by $7.4 \pm 0.4 \mathrm{mmol} / \mathrm{l}$ and reliably was higher than the same value in control under glucose load. Hyperglycaemia kept on maximal level during the following $30 \mathrm{~min}$, and initial concentration established only by 150 min of investigation. Blood glucose level decreased to the same value as under glucose load by $180 \mathrm{~min}$.

Thus, calcitonin injection didn't tell on the initial blood glucose level but increased the degree and duration of hyperglycaemia. The decreasing of glucose tolerance fond its expression in the values of hyperglycaemic coefficients: $1.713 \pm 0.05$ against the background of calcitonin and $1.436 \pm 0.04$ under control $(\mathrm{P}<0.001)$. Hypoglycaemic coefficient didn't differ reliably.

It is known, that, in the first place, the shifts in carbohydrate metabolism caused by the disturbance of insulin secretion and revealed in the type of compensational hyperinsulinemia or in the type of glucose tolerance impairment. In case of alimentary hyperglycaemia in children with the 1-st degree obesity against the background of calcitonin injection marked reliably the impairment of glucose tolerance.

These results coincide with the data of other investigations [37] and indicate that calcitonin excess can be as "risk factor" with respect to diabetes mellitus. Despite on what that the overweight of normal body mass was the same in boys and in girls, the curves of alimentary hyperglycaemia characterized by the definite differs.

The rise of blood glucose level in girls was reliably higher than in boys in 30 and 60 min after the load even under control (Figure 2); the value of hyperglycaemic coefficient was higher respectively. Against the background of calcitonin the blood glucose level in girls was higher than in boys in 60, 90, 120 and 180 min after the load, the hyperglycaemic coefficient was reliably higher too.

As testified our received findings, the endocrine regulation of glucose homeostasis in girls occurred more sensitive to calcitonin effect than in boys. Sex differences must be taken into consideration in calcitonin treatment. Besides one should mean that the increasing secretion of calcitonin occurs in stress situations, in this connection hypercalcitoninemia arises [38]. In these conditions endogenous calcitonin can make the same effect on the regulation of carbohydrate metabolism as exogenous injec- tions of hormone. As far as the development of mellitus diabetes in children is associated with viral infections, stressful events, puberty, and an increase of the incidence of mellitus diabetes occurs between the age of $10-14$ years [20,32], what, in our opinion, our data are worthy of attention and further investigation.

The impairment of glucose tolerance in children with the 1-st degree obesity under glucose tolerant test per os against the background of calcitonin injection revealed in our investigations is one of clinic manifestations of insulin-resistance. Although some authors consider the decreasing of the ratio of blood glucose concentration by insulin level as more significant index of insulin-resistance in children and adolescents with obesity [39], but other authors [40] believe that in the assessment of insulin-resistance under the obesity in children and adolescents the meaning of the stimulating insulin output and Matsuda's index, determining by the data of oral glucose tolerant test, possesses more diagnostic significant. Nevertheless, the establishment of diagnosis of the disturbance of glucose tolerance or hyperglycaemia on an empty stomach allows reveal the persons with high risk of the development of mellitus type 2 diabetes and cardiovascular diseases [17].

Insulin-resistance is considered as non-capacity of organism to use effectively insulin, secreted by it. For example, insulin-resistance of skeletal muscles mainly caused by the defects of insulin-dependent glucose transport [41]. Insulin-resistance is the common metabolic disorder which plays the leading role in pathogenesis of metabolic syndrome and also mellitus type 2 diabetes and obesity.

A number of hormones such as entero-glucagon, corticotrophin, vasopressin, somatotropin, thyrotropin, prolactin, thyroxin, or intensify, or decrease insulin effect $[17,41]$ and, so, intensify or decrease insulin-resistance. Earlier we were showed the slowdown of glucose-stimulated insulin secretion under calcitonin injection [42]. Other authors [43] revealed a diabetogenic effect of salmon calcitonin, its inhibitory effect on insulin secretion, stimulating effect on gluconeogenesis and inhibitory effect on glycogenesis. As far as insulin effect can be modified by calcitonin effect so one can suppose about its potential role in pathogenesis of these diseases.

\section{CONCLUSION}

Thus, we can conclude that calcitonin injection exposes more significant rise of blood glucose level after glucose load in children with the 1-st degree obesity than in control, i.e. leads to glucose intolerance. The girls with the 1-st degree obesity characterized more sensitivity to the hyperglycemic effect of calcitonin than the boys. Sex specificities of calcitonin effect on glucose metabolism 
must be taken into consideration in calcitonin treatment.

\section{REFERENCES}

[1] Rolland-Cachera, M.E., Peneau, S. and Bellisle, F. (2007) Metabolic syndrome definition in children: A focus on the different stages of growth. International Journal of Obesity, 31, 1760.

[2] Viner, R.M., Hindmarsh, P.S., Tayler, B. and Cole, T.I. (2008) Childhood body mass index (BMI), breastfeeding and risk of type I diabetes: Findings from a longitudinal national birth cohort. Diabetic Medicine, 25, 1056-1061. doi:10.1111/j.1464-5491.2008.02525.x

[3] Phelan, S., Wadden, T.A., Berkowitz, R.I., et al. (2007) Impact of weight loss on the metabolic syndrome. International Journal of Obesity, 31, 1442-1448. doi:10.1038/sj.ijo.0803606

[4] Ageeva, V.V., Krasil'nikova, E.I., Zubina, I.M. and Shlyakhto, E.V. (2002) Relation between insulin-resistance and lipid metabolism dysfunction in patients with obesity. Terapeutical Ackhiv, 74, 12-15.

[5] Finegood, D.T. (2003) Obesity, inflammation and type II diabetes. International Journal of Obesity, 27, 1-5. doi:10.1038/sj.ijo.0802490

[6] Nugent, A.P. (2004) The metabolic syndrome. Nutrition Bulletin, 29, 36-43. doi:10.1111/j.1467-3010.2004.00403.X

[7] Wilkin, T.Y. (2001) The accelerator hypothesis: Weight gain as the missing link between type I and type 2 diabetes. Diabetologia, 44, 914-922. doi:10.1007/s001250100548

[8] Lofgren, P., Hoffstedt, J., Naslund, E., et al. (2005) Protective and controlled studies of the actions of insulin and catecholamine in fat cells of obese women following weight reduction. Diabetologia, 48, 2334-2342. doi:10.1007/s00125-005-1961-6

[9] Muacevic-Katanec, D., Vetelko, Z., Busljeta, I. and Car, N. (2003) Recommendations on the approach to obese persons with diabetes mellitus. Diabetes Croatian, 32, 315.

[10] Eriksson, J.G. (2006) Early growth, and coronary heart disease and type 2 diabetes: Experiences from the helsinki birth cohort studies. International Journal of Obesity, 30, 518-522.

[11] Dumie, M., Spehar, A. and Janjanin, N. (2004) Debelo dijete. Paediatr Croat, 1, 3-8.

[12] Dianov, O.A., Gnusaev, S.F., Yakovlev, B.N. and Gorshkova, M.I. (2008) Neurocirculatory instability and metabolic disturbances in children with obesity and their correction. Vestn. Pediatr. Farmakol. I Nutritsiol., 5, 3438.

[13] Zhu, J.-F., Liang, L., Wang, S.-L. and Zhou, C.-C. (2006) Distribution of complication in juveniles with moderate and heavy obesity. Journal of Applied Clinical Pediatrics, 21, 1320-1321.

[14] Zhang, X.N., Yu, S.G. and Li S.N. (2003) The level of insulin and c-peptide in the blood plasma of children with simple obesity. Journal of Applied Clinical Pediatrics, 18, 28-29.

[15] Liu, R.H., Mizuta, M., Kurose, T. and Matsukura, S. (2002) Early events involved in the development of insulin resistance in zuker fatty rats. International Journal of Obesity, 26, 318-326. doi:10.1038/sj.ijo.0801924

[16] Orlov, R.S. and Nozdrachev, A.D. (2006) Normal'naya fiziologiya (Common physiology), Moscow.

[17] Roitberg, G.E. (2007) Metabolicheskii sindrom (Metabolic syndrome). Moscow.

[18] Fox, K.R., Peters, D.M., Sharpe, P. and Bell, M. (2000) Assessment of abdominal fat development in young adolescents using magnetic resonance imaging. International Journal of Obesity and Related Metabolic Disorders, 24, 1653-1659. doi:10.1038/sj.ijo.0801464

[19] Krishnaveni, G.V., Veena, S.R., Hill, J.C., et al. (2010) Intrauterine exposure to maternal diabetes is associated with higher adiposity and insulin resistance and clustering of cardiovascular risk markers in Indian children. Diabetes Care, 33, 402-404. doi:10.2337/dc09-1393

[20] Dedov, I.I., Kuraeva, T.L. and Peterkova, V.A. (2008) Sakharnyi diabet u detei i podrostkov (Pancreatic diabetes in children and juveniles). GEOTAR-Media, Moscow.

[21] Pavlovskaya, E.V., Strokova, T.V., Surkov, A.G. and Kaganov, B.S. (2008) Obesity in children and juvenilesPresent view on the problem. Vopr. Det. Dietol., 6, 27-36.

[22] Szurkowska, M., Szafraniec, K., Gilis-Januszewska, A., et al. (2006) Metabolic hazzars of obesity. Polish multicenter study on diabetes epidemiology: EA-EEF European Congress of Epidemiology "Epidemiology and Health Care Practice”. Utrecht, 29 June-1 July 2006, 141.

[23] Demidova, T.Y. and Kruglova, E.L. (2009) Obesity as a key and modifying reason causing the II type pancreatic diabetes. Russian Medicine, 7, 450.

[24] Cruz, M.L., Shaibi, G.Q., Weigensberg, M.J., et al. (2005) Pediatria obesity and insulin resistance: Chronic disease risk and implications for treatment and prevention beyond body weight modification. Annual Review of Nutrition, 25, 435-468. doi:10.1146/annurev.nutr.25.050304.092625

[25] Dubois, L. and Girand, M. (2006) Early determinations of overweight at 4.5 years in a population-based longitudinal study. International Journal of Obesity, 30, 610-617. doi:10.1038/sj.ijo.0803141

[26] Kahn, B.B. and Flier, J.S. (2000) Obesity and insulin resistance. International Journal of Obesity, 106, 473481.

[27] Freemark, M. (2010) Pediatric obesity in etiology, pathogenesis and treatment (Contemporary endocrinology). Humana Press, New York.

[28] Kovarenko, M.A. and Ruyatkina, L.A. (2006) Reflections on the debut of the metabolic syndrome in obese children with pink striae. Byul. Vost.-Sib. Nauch. Tsentra SO RAMN, 1, 22-26.

[29] Leont'eva, I.V. (2008) Metabolic syndrome as pediatric problem. Ros. Vestn. Perinatol. I Pediatr., 53, 4-16.

[30] Potemkin, V.V., Troitskaya, S.Y. and Tomilova, E.N. (2006) Pathophysiological mechanisms of insulin-resistance at obesity. Ros. Med. Zhurn., 2, 20-23. 
[31] Druet, C., Dabbas, M., Baltakse, V., et al. (2006) Insulin resistance and the metabolic syndrome in obese french children. Endocrinology, 64, 672-678.

[32] Dedov, I.I., Mel'nichenko, G.A. and Fadeev, V.V. (1998) Endokrinologiya: Kratkii spravochnik (Endocrinology: Summary reference book). Moscow.

[33] Butakova (Moisa), S.S. and Nozdrachev, A.D. (2010) Calcitonin-Contra-insulin hormone. Advances of Gerontology, 23, 364-370.

[34] Gattereau, A., Bielmann, P., Durivage, J., et al. (1977) Hyperglycaemic effect of synthetic salmon calcitonin. Lancet, 310, 1076-1077. doi:10.1016/S0140-6736(77)91908-0

[35] Evans, I.M., Joplin, G.F. and Mac Intyre, J. (1977) Hyperglycaemic effect of synthetic salmon calcitonin. Lancet, 2, 1.76-1077.

[36] Freed, W.J., Perlow, M.J. and Wyatt, R.J. (1979) Calcitonin: Inhibitory effect on eating in rats. Science, 206, 850-852. doi:10.1126/science.493987

[37] Passariello, N., Guigliano, D., Sgambato, S., et al. (1981) Calcitonin, a diabetogenic hormone? The Journal of Clinical Endocrinology \& Metabolism, 53, 318-323. doi:10.1210/jcem-53-2-318
[38] Drzhevetskaya, I.A., Mishina, N.F., Limanskii, N.N., et al. (1982) Secretion and functional reserve of calcitonin in man. Neuroendocrine Mechanisms of Adaptation. Stavropol, 4-12.

[39] Borodina, O.V., Odud, E.A., Timofeev, A.V., et al. (2003) Assessment of insulin resistance in children and adolescents with obesity. Problemy Endokrinologii/Problems of Endocrinology, 49, 8-11.

[40] Vasyukova, O.V. and Vitebskaya A.V. (2009) Insulin resistance under obesity in children: Argument of assessment. Problemy Endokrinologii/Problems of Endocrinology, 55, 8-13.

[41] Nozdrachev, A.D. (2002) The fundamentals of physiology. St.-Petersburg.

[42] Iaroshevskii, I.A., Darinskii, I.A. and Butakova (Moisa), S.S. (1989) Effect of calcitonin on insulin and glucagons secretion by the pancreas. Problemy Endokrinologii/Problems of Endocrinology, 35, 58-61.

[43] Young, A.A., Wang, M.W., Gedulin, B., et al. (1995) Diabetogenic effects of salmon calcitonin are attributable to amylin-like activity. Metabolism-Clinical and Experimental, 44, 1581-1589. doi:10.1016/0026-0495(95)90079-9 